\title{
Las noticias falsas (fake news), la desinformación y la infodemia durante la pandemia de la CovID-19
}

Fake news, disinformation and infodemy
during the covID-19 pandemic

José Luis Vázquez Luna*

Universidad Anáhuac México

Av. Universidad Anáhuac núm. 46,

Col. Lomas Anáhuac, C. P. 52786, Huixquilucan,

Estado de México, México

Editor: Rogelio del Prado Flores

Fecha de recepción: 6 de julio de 2020

Fecha de aceptación: 22 de julio de 2020 jvazquez@anahuac.mx

https://orcid.org/0000-0002-8808-5023

https://doi.org/10.36105/stx.2020edespcovid-19.09

\section{RESUMEN}

La madurez de las Tecnologías de Información y Comunicación (TIC) ha detonado un crecimiento exponencial de información en todas las áreas del conocimiento y durante la pandemia se ha incrementado, en especial, el tema del coronavirus. El presente trabajo se desarrolló utilizando una investigación documental con carácter descriptivo, con una metodología cualitativa e interpretativa. El objetivo que se persigue es analizar cómo se ha difundido la información sobre la pandemia de la COVID-19 dando paso a la llamada infodemia, cómo las noticias falsas (fake news) han sido difundidas a través de las redes sociales, y cuáles han sido las estrategias implementadas por diferentes autoridades y sitios de Internet para combatirlas y disminuir su impacto en la sociedad. Como resultado del análisis se determinó la necesidad de una alfa-

\footnotetext{
* Doctor en Comunicación Aplicada por la Universidad Anáhuac México, tiene una maestría en Administración de Negocios, por la Escuela Superior de Comercio y Administración, del IPN, y la licenciatura en Biblioteconomía, por la Escuela Nacional de Biblioteconomía y Archivonomía (ENBA). Es Investigador Asociado del Centro de Investigación para la Comunicación Aplicada (CICA) de la Universidad Anáhuac México, y forma parte del Seminario de Información y Sociedad, del Instituto de Investigaciones Bibliotecológicas y de Información (IIBI) de la UNAM; ha impartido conferencias en foros nacionales e internacionales. Su más reciente publicación, el capítulo de libro "Tecnologías de Información y Comunicación y su impacto en la transformación de las bibliotecas del siglo xxI".
} 
betización digital de la sociedad para que pueda identificar la información que es confiable y segura, y descartar las noticias falsas.

Palabras clave: infodemia, noticas falsas, alfabetización digital, fake news, desinformación.

\section{ABSTRACT}

The maturity of Informaction and Comnunication Technolgies (ITC) has triggered an exponential growth of information in all areas of knowledge and during the pandemic the topic of coronavirus has increased, especially. This work was developed using documentary research with character descriptive, with a qualitative and interpretive methodology, the objective is to analyze how information on the COVID-19 pandemic has been disseminated, giving way to the so called infodemic, how fake news has been disseminated through social networks, and what have been the strategies implemented by different authorities and Internet sites. As a result of the analysis it was determined, the need for a Digital Literacy of the society so that it can identify the information that is trustworthy and safe, and discard the false news.

Keywords: infodemic, fake news, digital literacy, disinformation.

\section{NTRODUCCIÓN}

L

a comunicación es la fuerza cohesiva de la sociedad que ha permitido a sus integrantes compartir e intercambiar ideas y pensamientos, no solo a través de la palabra, sino también con el lenguaje no verbal, en la interacción interpersonal. En los últimos años, la proliferación de las tecnologías de información y comunicación (TIC) ha detonado un crecimiento exponencial de información en todas las áreas del conocimiento, pero debido a la situación de salud que está viviendo la población mundial desde principios de este año con el contagio del coronavirus (CoviD-19), el crecimiento se ha inclinado considerablemente sobre este tema (Rizo García, 2006).

Las pandemias, las noticias falsas y la desinformación, no son fenómenos nuevos, han existido desde tiempos remotos, así podemos hacer referencia a la 
primera pandemia registrada en la historia que se da en el Imperio bizantino, del emperador Justiniano, y es una epidemia de peste, así como otras en el paso del tiempo. Pero más recientemente, ya en el siglo pasado, en 1918, durante los últimos meses de la Segunda Guerra Mundial, se presentó la llamada gripe española, que mató entre 20 y 50 millones de personas; en 1957 la conocida gripe asiática (H2 N2), que mató a un millón de personas; diez años más tarde hubo otro virus conocido como $\mathrm{H}_{3} \mathrm{~N} 2$ (gripe de Hong Kong), el cual afectó a un número similar de personas que la gripe asiática; en 1981 apareció el VIH/sida, que causó la muerte de 25 millones de personas; para 2009 se conoció el virus llamado (H1N1) o gripe porcina, la cantidad de muertos que reportaron las autoridades fue de 575 000, sin embargo, por lo complejo de la enfermedad, no se conoció el número real de fallecidos. En esta pandemia, las redes sociales no tuvieron una presencia muy significativa, probablemente porque estaban en su etapa de expansión pues Facebook apenas tenía 500 millones de usuarios y Twitter, 58 millones, lo cual representa la quinta parte de los usuarios que tienen hoy en día, pero lo que sí fue un hecho es que los modelos de comunicación social tuvieron que replantearse consistentemente (Pané, 2020) (Prnoticias, 2020) (Tufte, T., 2017).

Hoy nuevamente la sociedad mundial enfrenta una crisis de salud por la pandemia del coronavirus (covid-19), que a la fecha (junio de 2020) ha cobrado millones de muertes y aún no se puede conocer el impacto total, pues el país se encuentra en medio del trance. Este problema se ha conocido mucho más que los anteriores debido a que las redes sociales están en su mayoría de edad y la cantidad de personas que las utilizan son: en Facebook, 2449 millones y YouTube, 2 000 millones (Statista, 2020).

Respecto a las noticias falsas, como se mencionó, tampoco es un fenómeno nuevo, a lo largo de la historia, algunos de los engaños más conocidos fueron: en 1522, cuando el autor italiano y satírico Pietro Aretino, escribió sonetos malvados, panfletos y obras de teatro, él utiliza sus cartas para chantajear a los clientes y amigos, y si ellos no pagaban el chantaje, sus intimidades eran publicadas; también publicó su correspondencia con la nobleza de Italia (Darnton, 2017). En 1710 Jonathan Swift escribió su ensayo The Art of Political Lying, en su obra, trata la naturaleza de la mentira política, la cual es utilizada para inducir a las personas a creer que las falsedades dichas sirven para un fin saludable, y da las reglas para calcular el valor monetario de las mentiras (Purdy, G. W., 2013).

En 1844, el escritor Edgar Allan Poe escribió un artículo periodístico en el que mencionaba que un globo había cruzado el Atlántico en solo tres días, noticia que 
fue desmentida a los cuatro días. A este autor se le acredita haber escrito otras seis historias que resultaron ser noticias falsas. Por otra parte, Orson Welles escribió The War of the Worlds, que fue publicado como libro en 1898 y hablaba de una invasión extraterrestre, posteriormente, en 1938, se transmitió una emisión de radio basada en esta misma obra y quienes no escucharon la presentación consideraron que era verdad y generó cierta incertidumbre.

En épocas más recientes, algo de lo más conocido y difundido fue la campaña política de Donald Trump en 2016, en donde se decía que el gobierno de Rusia había apoyado al candidato a presidente a ganar la elección y las noticias falsas propiciaron que un alto porcentaje de los simpatizantes del presidente Obama no apoyara a Hillary Clinton. Esto validado por un estudio realizado por investigadores de la Ohio State University (Blake, 2018).

El término desinformación tampoco es muy reciente, tiene sus orígenes a finales de la Primera Guerra Mundial (1918) cuando los rusos referían que la policía política bolchevique utilizaba el término desinformatzia, para referirse a las acciones encaminadas a impedir la consolidación del régimen comunista en Moscú, por lo que la práctica de este fenómeno se vio fuertemente vinculado a la Guerra Fría entre la Unión Soviética y Estados Unidos, que crearon organismos especializados en utilizar la información como arma de guerra (Rodriguez, A., 2018), sin embargo, el concepto traspasó las fronteras y ya no solo es utilizado en el contexto político y económico, ha llegado a nuestros días y es utilizado en el lenguaje común, y podemos comprobarlo al realizar una consulta en un buscador (Google), al ingresar desinformación, arroja 350000 resultados y con el término desinformation ofrece 5470000 resultados, además, con este segundo término, nos da como sugerencia utilizar misinformation, al correr la búsqueda arroja 34500000 resultados (Estrada-Cuzcano, junio 2020). Pero entonces, cuál es la similitud y/o diferencia entre ellos, Galdón (2001) establece que la misinformation se da cuando se transmite o da a conocer una información equivocada, por error, mientras que la desinformación se produce cuando hay una intención clara de engañar a un público, por parte de los realizadores de la información (p. 48), pero ya sea por error o intencional, se trata de una información inexacta. Sobre el tema, la Real Academia de la Lengua ofrece una definición muy escueta: "1. (f.) Acción y efecto de desinformar, y 2. (f.) Falta de información o ignorancia", y sobre desinformación nos dice: "1. (tr.) Dar información intencionadamente manipulada al servicio de ciertos fines, y 2. (tr.) Dar información insuficiente y omitirla". Por lo que dentro de estas definiciones se pueden abarcar las dos 
intenciones destacadas entre estos términos, es decir, el error y la intención de mentir. La Organización Panamericana de la Salud (ops) (1 mayo, 2020) coincide con la definición de desinformación como "la información falsa o incorrecta con el propósito deliberado de engañar".

\section{METODOLOGÍA}

El presente trabajo se desarrolló utilizando una investigación documental con carácter descriptivo, con una metodología cualitativa e interpretativa, la cual determinó el procedimiento de selección, acceso y registro de la muestra documental (por interés del autor), como instrumento de análisis se construyó una matriz para el registro de contenido relacionado con: infodemia, noticas falsas y desinformación. El objetivo que se persigue es analizar cómo se ha difundido la información sobre la pandemia de la CoviD-19 dando paso a la llamada infodemia, cómo las noticias falsas (fake news) han sido difundidas a través de las redes sociales, y cuáles han sido las estrategias implementadas por diferentes autoridades y sitios de Internet para combatirlas y disminuir su impacto en la sociedad.

La hipótesis que se plantea para este trabajo es: A menor alfabetización digital por parte de los usuarios de las redes, mayor es la desinformación y la proliferación de noticas falsas.

\section{DISCUSIón}

Las redes sociales han sido utilizadas para la difusión y propagación de noticias falsas, lo cual ha generado una desinformación en la sociedad, sin embargo, no debemos juzgar a las redes como las causantes de esta situación, finalmente ellas son una herramienta utilizada por las personas que se valen de estas herramientas, en algunos casos, para alcanzar sus medios, pues hay personas que difunden información con la idea de crear una situación en la sociedad o logar un objetivo económico o político, en este caso se debería analizar la cuestión ética o falta de ella por parte de quienes utilizan la información y los medios con estos fines.

En otro grupo están las personas comunes que sin buscar un fin económico o de lucro difunden los mensajes que reciben sin reflexionar sobre la veracidad de la información, esto se puede deber a querer ser los primeros en compartir el 
mensaje, el querer obtener "Me gusta" en sus publicaciones. Este comportamiento puede ser estudiado desde un enfoque sociológico considerando que las personas, una vez satisfechas sus necesidades básicas, buscan cubrir sus requerimientos más elevados, como el reconocimiento, y para lograrlo se valen de publicar memes, noticias o información que no tiene un sustento que valide los datos que contienen; otro enfoque para analizar este comportamiento es el de la cultura del desapego y la inmediates, donde lo importante es la gratificación o satisfacción momentánea, lo cual lleva a la persona a buscar la aceptación inmediata y en caso de no recibir un "Me gusta" o una vista en sus publicaciones les genera una frustración, esta conducta está acompañada de un desdén hacia el esfuerzo.

Las noticias falsas (fake news), la desinfomación, la missinformation, y la infodemia, son fenómenos que han existido desde hace mucho tiempo y que afectan y alteran la vida de las personas en la sociedad. El uso de las redes sociales han exponenciado su propagación debido a la facilidad con que se pueden generar y difundir; entre los efectos que pueden provocar en las personas está: la ansiedad, la depresión y el agotamiento emocional. Como un claro ejemplo de estos trastornos fue el desabasto que se produjo cuando la gente se volcó a los supermercados a comprar productos para enfrentar la pandemia, entre ellos se encontraban: gel antibacterial, jabón, mascarillas o cubrebocas y algo muy curioso y difícil de entender, la compra de papel higiénico, que las personas llevaban al por mayor.

Los factores mencionados anteriormente pueden no ser conocidos o ser conscientes para las personas que comparten la información sin reflexionar sobre su veracidad y el efecto que puede tener en la sociedad, pero si estuvieran interesados en verificarla, qué tanto conocer de cómo hacerlo, de cuáles son los medios para llevarlo a cabo, esto es algo que la sociedad misma debe poner atención y generar mecanismos para desarrollar habilidades en las personas para evitar la desinformación y las noticias falsas.

\section{REDES SOCIALES, DESINFORMACIÓN E INFODEMIA}

La interacción y comunicación de las personas ha dado un giro muy significativo con las redes sociales, ahora, en cuestión de minutos pueden enterarse de acontecimientos que están sucediendo en lugares muy distantes a donde se encuentran y la convivencia con las personas también se ha visto afectada ya que en ocasiones se tiene más comunicación con gente que se encuentra lejos del usuario de la red 
que con los más cercanos, incluidos los miembros de su familia. Hoy, la sociedad está saturada de aplicaciones como Facebook, WhatsApp, Instagram, Twitter, LinkedIn, Snapchat, etc., que si bien es cierto han incrementado la posibilidad de compartir información y estar en contacto con personas que se encuentran en lugares lejanos, también de alguna forma se han convertido en un problema (Plottier, 2015) (Rizo, 2007), pues además de los beneficios ofrecidos, se enfrenta el problema de las noticias falsas o la desinformación, que han querido ser erradicadas por autoridades y aplicaciones de redes sociales, pero al enfrentarse al dilema de estar coartando la libertad de expresión hace difícil definir los criterios a seguir para poder hacerlo.

En el contexto de la pandemia de la Covid-19 que se está viviendo a nivel mundial, se ha acuñado otro término, infodemia, al cual la Organización Panamericana de la Salud (OPS) y la Organización Mundial de la Salud (omS) (1 mayo, 2020) se refieren como "un gran aumento del volumen de información relacionada con un tema particular, que puede volverse exponencial en un periodo corto debido a un incidente concreto como la pandemia actual", es decir "una epidemia de información" la cual se produce e intercambia en todas partes del mundo y llega a millones de personas, el problema es saber, ¿cuál de la información compartida es correcta y cuál no? Este fenómeno, más allá de ayudar a combatir los contagios, ha propiciado una desinformación que ha obstruido el control de la enfermedad y ha generado miedo y desconcierto en la población e inclusive, en lugar de fomentar la unión y solidaridad, ha creado una división entre la gente, por lo que han considerado que la desinformación causada por la infodemia puede ser tan peligrosa como el mismo virus (Ghebreyesus, \& Ng, 18 febrero 2020), (Infobae, 4 abril 2020). En un estudio de Reuters Institute (2019) se menciona que, en Estados Unidos, el $45 \%$ de las personas que utilizan redes sociales para informarse no se preocupan por detenerse a preguntar si lo que están consumiendo es falso o verdadero, el $65 \%$ restante se lo llega a preguntar, pero no indican qué porcentaje verifica la fuente.

Las noticias falsas que se han difundido a través de las redes sociales también han generado odio y discriminación incluso contra los mismos trabajadores de la salud a quienes se les ha negado el servicio de transporte para trasladarse a sus lugares de trabajo o han sido agredidos, física o verbalmente, por personas que consideran que ellos están propagando el contagio (Expansión Política, 10 de abril 2020), o aquellas que se han basado en teorías conspiratorias como decir que es un intento por despoblar deliberadamente el planeta, que se quiere 
terminar con los adultos mayores, que Bill Gates y la red 5G están conspirando para controlar el mundo e implantar con la vacuna un chip a las personas y poder manipularlas, la que menciona que los soldados por la noche esparcen el virus por las calles de la ciudad, o que en los hospitales están matando deliberadamente a los enfermos, comer ajo previene el contagio, puedes matar el virus rociando todo el cuerpo con alcohol o coloro, tomar un baño caliente previene la transmisión de la coviD-19,todas estas afirmaciones se han propagado sin tener ningún soporte válido o comprobación previa para sostenerlas (Equipar, 2020) (Ghebreyesus, 18 de febrero 2020) (Infobae, 7 de mayo 2020) (Infobae, 5 de julio 2020) (OPS, 1 de mayo 2020) (Pacheco, 6 de mayo 2020).

De acuerdo con un análisis hecho por el Centro de Informática de la Salud de la Universidad de Illinois, citado por la Organización Panamericana de la Salud (1 de mayo 2020) en marzo, se publicaron 550 millones de tuits y los hashtags más utilizados en la región de las américas fueron: \#Covid-19, \#CoviD_19, \#aplanarlacurva y \#pandemia. En ese mismo periodo se han subido a YouTube 361000000 millones de videos sobre este tema y se han publicado cerca de 192000 artículos en Google Schoolar. De toda esta información publicada un alto porcentaje (80\%) no es válida y esto lo confirma el estudio "Radiografía sobre la difusión de fake news en México", que coloca al país como el segundo generador de noticas falsas solo atrás de Turquía. Por su parte, el sitio web periodístico News Guard, que califica la credibilidad de los portales de noticias, concluyó que la información falsa es mucho más que la información confiable (Aristegui Noticias, 23 de abril 2020). Esto se debe, en buena parte, a la existencia de una industria que se dedica a producir noticias falsas, que difunde y promueve todo tipo de información, con la única finalidad de conseguir clics para convertirlos en dinero. Una muestra de esta situación la presentó Miller (12 de noviembre 2018) de la BBC Clic, en una entrevista a un emprendedor que era propietario de una docena de sitios web dedicados a este negocio.

Como se puede observar en el análisis realizado sobre el comportamiento de la sociedad, en la difusión y propagación de las noticias falsas, es un problema grave que afecta a diversos ámbitos como el económico, cultural y sobre todo el de salud. Ante esta situación, diversas organizaciones y aplicaciones de redes sociales están haciendo un gran esfuerzo para combatirlas. Al respecto, el catedrático de la Universidad del Valle de México, Rubén Uriel Rivero Pardo, en una entrevista ofrecida a Aristegui Noticas (23 de abril 2020), destacó que es necesario que las personas se rodeen de fuentes oficiales y medios confiables para obtener infor- 
mación; por otra parte, otro experto en medios y profesor del Tec., Campus Guadalajara, Juan Villalobos (26 de junio 2020) recomienda las siguientes acciones para hacer frente a este problema:

1. Cultivar el escepticismo. No descartar de entrada todo lo que leemos, pero estar conscientes de que todo puede ser verdad, pero también mentira. Recordar que en estos tiempos algunos medios sacrifican rigor editorial en favor de la velocidad. Lo que nos lleva al siguiente punto.

2. Quién difunde la noticia. Es importante conocer los conflictos de interés de quien difunde la información o expresa su opinión.

Esto evita que se den como verdaderos hechos que benefician intereses económicos de las empresas que financian la investigación.

3. Eliminar nuestras fobias y filias al leer. Con el propósito de darle valor a la noticia por sí sola; es decir, dejar de lado nuestra opinión sobre ciertos comunicadores.

4. Buscar evidencia de lo que se dice. Por ejemplo, dentro de la contingencia por el coronavirus existe una controversia sobre la aplicación masiva de pruebas rápidas.

En lugar de aceptar la opinión de su periodista o funcionario favorito, es mejor revisar si los especialistas consideran que ayudan a combatir mejor la epidemia.

5. No quedarnos solo con información que refuerza nuestro punto de vista. Revisar qué dicen los medios y personas que piensan distinto a nosotros. Escuchar lo que el otro tiene que decir es la mejor manera de construir la conversación y basar nuestros puntos de vista en argumentos no opiniones.

6. Entender la diferencia entre correlación y causalidad. Que dos cosas sucedan al mismo tiempo no quiere decir que una sea causa de la otra.

Por su parte, el fundador y CEO de Facebook, Mark Zuckerbrg, consideró como un reto personal la lucha contra la desinformación y las noticias falsas y menciona que esta plataforma aumentó la seguridad y cerró varios de estos sitios en un intento de detener el aumento de estos negocios. Al introducir el término coro- 
navirus, en la función de búsqueda, el primer resultado orienta a los usuarios a consultar el portal de la oms para obtener información confiable sobre el tema (Miller, 12 de noviembre 2018) (Ghebreyesus, 18 de febrero 2020). Otro esfuerzo es el realizado por WhatsApp, que liberó su verificador de información, avalado por la Red Internacional de Verificación de Datos (IFCN); esta herramienta, en su versión en español ha sido utilizada en ocho países de América Latina (Argentina, Bolivia, Colombia, Ecuador, México, Paraguay, Perú y Venezuela), además de España (Chávez, 26 de mayo 2020), la plataforma de YouTube, cuando presenta un video que ofrece información sobre el coronavirus, despliega una liga para llevar al usuario al portal de la oms (Ghebreyesus, 18 de febrero 2020). En otro esfuerzo, Twitter, clasificará los tuits con información sobre coronavirus con tres etiquetas según el contenido que se despliegue, así, cuando los datos sean identificados como falsos, el tuit será etiquetado y removido, si el tuit no es confirmado o puede ser cuestionable, se etiquetará como advertencia; finalmente, si no se tiene la certeza de su veracidad pero puede ser cuestionable, no se etiquetará ni se tomará alguna acción contra ese tuit (Expansión, 12 de mayo 2020).

La lucha contra las noticias falsas no es exclusiva del tema del coronavirus, también las hay en otras áreas del conocimiento y así se describen siete sitios que tratan de contrarrestar este fenómeno que afecta a la sociedad (Elósegui, 28 de octubre 2017).

1. FactCheck.org: analiza la información generada por los principales políticos estadounidenses, en comunicados de prensa.

2. Snopes: investiga las leyendas urbanas, es uno de los sitios más populares, por desmentir mentiras y rumores.

3. La Buloteca: snaliza de forma manual los reportes y desmentidos para avalar que la procedencia sea de fuentes confiables.

4. VOST (Virtual Operation Support Team): trabaja la sección \#StopBulos, que recopila las noticias falsas aparecidas en internet para detener su propagación y ratificar su falsedad.

5. Hoaxy: verifica las noticas dadas en Internet.

6. CazaHoax: analiza las noticas virales. 
En el ámbito académico, la International Federation of Library Association (IFLA) también ha hecho una serie de recomendaciones para que los alumnos y profesores desarrollen sus habilidades informacionales que les permitan detectar las noticas falsas. Dentro de los puntos mencionados por la federación se encuentran: estudiar la fuente, revisar cuál es la historia completa, quién es el autor, revisar las fuentes adicionales, si tiene datos que avalen la información presentada, comprobar la fecha, que sean noticias actuales, analizar si no se trata de una broma, considerar si las creencias o pensamiento del usuario pudiera alterar la opinión sobre una información y, finalmente, preguntarle a un experto para verificar la información.

Las recomendaciones de la IFLA van de la mano con lo que se conoce como alfabetización digital, cuyo objetivo es enseñar a las personas a utilizar adecuadamente las herramientas tecnológicas con un sentido crítico y desarrollando la capacidad para analizar la información, es decir, localizar, evaluar, ordenar y discernir sobre la información que aparecen en Internet (Wordpress, 28 de junio 2008). En la medida que las personas tengan una mayor alfabetización digital e informacional, se podrá combatir las noticias falsas que tanto daño han hecho a la sociedad, sobre todo en los últimos tiempos, durante la contingencia de la COVID-19.

\section{CONCLUSIONES}

La pandemia del coronavirus que se está viviendo ha modificado la forma de interacción, convivencia y comunicación de la sociedad, y seguirá modificándola cuando se regrese a la nueva normalidad donde encontraremos un desarrollo y uso considerable de las redes sociales y una nueva forma de reunirnos y de trabajar. Una de las principales afectaciones que se tendrán al pasar esta emergencia, es la desinformación y la infodemia que evitaron que muchas personas pudieran salvar la vida por tener datos erróneos sobre la forma de combatir el contagio e inclusive el que creyeran que no era cierta la contingencia.

Al finalizar el análisis de los documentos y de la información publicada se puede concluir que las personas que comparten información en las redes sociales no están conscientes del daño y la afectación que están causando y que muchos de ellos lo consideran divertido y sin malicia, esto debido a la falta de un sentido crítico para discernir sobre la forma de manejar y compartir la información, y la 
falta de habilidad para identificar la información valida y verídica. Esta situación nos lleva a comprobar la hipótesis planteada que fue: A menor alfabetización digital por parte de los usuarios de las redes, mayor es la desinformación y la proliferación de noticas falsas, por lo que es necesario que los medios refuercen sus esfuerzos para combatir el flagelo de las noticias falsas y ayudar a que los usuarios de redes sociales desarrollen habilidades digitales que les permitan, por una parte, darse cuenta del problema que significa compartir información errónea y, por otra, saber identificar y determinar si una publicación tiene validez o no.

Finalmente, las unidades de información que están más cerca de los alumnos y profesores también deben reforzar los esfuerzos para generar programas de alfabetización informacional que les permitan identificar el tipo de información que están utilizando y se cree el hábito de verificar la fuente y validez de la información.

Queda pendiente llevar a cabo una investigación de campo donde se analice de forma directa con las personas, las causas que las llevan a compartir información sin alguna consideración.

\section{REFERENCIAS}

Aristegui noticias. (2020, 23 de abril). México, segundo país con mayor generación de noticias falsas de COVID-19. https://aristeguinoticias.com/2304/mexico/mexico-segundo-pais-con-mayor-generacion-de-noticias-falsas-de-covid-19

Blake, A. (2018,3 de abril). A new study suggests fake news might have won Donald Trump the 2016 election. The Washington Post. https://www.washingtonpost.com/news/ the-fix/wp/2018/04/03/a-new-study-suggests-fake-news-might-have-won-donaldtrump-the-2016-election/?noredirect=on\&utm term $=.63 \mathrm{e} 586 \mathrm{c} 71 \mathrm{ef} 8$

Chávez, G. (2020, 26 de mayo). Whatsapp y otros chatbots conta las noticias falsas y el CoviD-19. Expansión. https://expansion.mx/tecnologia/2020/05/26/whatsapp-yotros-chatbots-contra-las-noticias-falsas-y-el-covid-19

Darnton, R. (2017, 13 de febrero). The True History of Fake News. NYR Daily (blog), New York Review of Books. http://www.nybooks.com/daily/2017/02/13/the-true-historyof-fake-news/

Elósegui, L. (2017, 28 de octubre). Siete sitios para detectar noticias falsas. Verificado. https://verificado.com.mx/7sitios-detectar-noticias-falsas/

Equipar. (2020). Noticias falsas sobre el CoviD 19 invaden las redes sociales. https:// www.revistaequipar.com/noticias/noticias-falsas-sobre-el-covid-19 
Estrada-Cuzcano, A., Alfaro-Mendives, K., \& Saavedra-Vásquez, V. (2020, junio). Desinformation y misinformation posverdad y fake news: precisiones conceptuales, diferencias, similitudes y yuxtaposiciones. Información, cultura y Sociedad, 42. https://doi. org/10.34096/ics.i42.7427

Expansión Política. (2020, 10 de abril). Agresiones a personal médico van en aumento en medio de la epidemia del COVID-19. https://politica.expansion.mx/mexico/2020/04/10/agresiones-a-personal-medico-van-en-aumento-en-medio-de-la-epidemia-de-covid-19

Expansión Tecnología (2020,12 de mayo). Twitter etiqueta fake news sobre COVID-19 https://expansion.mx/tecnologia/2020/05/12/twitter-etiquetara-fake-news-sobre-covid-19?utm_source=internal\&utm_medium=branded

Galdón, G. (2001) “Información, desinformación y manipulación”. En Galdón, G. (coord.). Introducción a la comunicación y a la información (pp. 47-75). Ariel.

Ghebreyesus, T. A., \& Ng, A. (2020, 18 de febrero). Desinformación frente a medicina: hagamos frente a la infodemia. El País. https://elpais.com/sociedad/2020/02/18/actualidad/1582053544_191857.html

International Federation Library Association (IFLA). (2017). Cómo las bibliotecas pueden ayudar a conseguir soluciones reales para las noticias falsas. https://www.ifla.org/ ES/node/11631

Infobae. (2020, 4 de abril). Qué es a infodemia y cómo influye para promover la discriminación en media de la pandemia de coronavirus. https://www.infobae.com/america/ mexico/2020/04/04/que-es-la-infodemia-y-como-influye-para-promover-la-discriminacion-en-medio-de-la-pandemia-de-coronavirus/

Infobae. (2020, 7 de mayo). Tres noticias falsas sobre el coronavirus que recorren la red. https://www.infobae.com/america/mexico/2020/05/07/tres-noticias-falsas-sobreel-coronavirus-que-recorren-la-red/

Infobae. (2020, 5 de julio). Tres noticias falsas sobre el coronavirus que recorren la red. https://www.infobae.com/america/mexico/2020/05/07/tres-noticias-falsas-sobreel-coronavirus-que-recorren-la-red/

Miller, C. (2018, 12 de noviembre). Fake news: así funciona la industria de las noticias falsas con la que algunos jóvenes se ganan la vida en Europa del Este. BBC News. https://www.bbc.com/mundo/noticias-46163407

OPS (2020, 1 de mayo). Entender la infodemia y la desinformación en la lucha contra la coVID-19. https://www.paho.org/es/documentos/entender-infodemia-desinformacionlucha-contra-covid-19

Pacheco, M. (2020, 6 de mayo). ¡Cuidado! Las falsas noticias, son tan peligrosas como el mismo Covid-19. Forbes. https://forbescentroamerica.com/2020/05/06/cuidado-las-falsas-noticias-son-tan-peligrosas-como-el-mismo-covid-19

Pané, G. H. (2020). Grandes pandemias de la historia. National Geographic, Historia. https://historia.nationalgeographic.com.es/a/grandes-pandemias-historia_15178/5 
Plottier, J. L. (2015). Teoría de redes y fenómenos de comunicación: problemas metodológicos. Dixit (21), 56-67. https://doi.org/10.22235/d.v0i21.400

Prnoticias (2020, 23 de marzo). La pandemia virtual: las redes sociales en el impacto mediático del coronavirus. Prnoticias.com. https://prnoticias.com/2020/03/23/redes-sociales-en-el-impacto-mediatico/

Purdy, G.W. (2015, Oct-nov). A review of The Art of Political Lying by Jonathan Swift. Reviews \& Interviews. http://www.eclectica.org/v19n4/purdy_swift.html

Rizo, M. (2006). La interacción y la comunicación desde los enfoques de la psicología social y la sociología fenomenológica: breve exploración teórica. Analisi Quaderns de comunicacio i cultura. https://dialnet.unirioja.es/servlet/articulo?codigo=2136324

Rizo, M. (2007). Interacción y comunicación en entornos educativos: Reflexiones teóricas, conceptuales y metodológicas. E-Compós, 8. https:/doi.org/10.30962/ec.143

Rodriguez, R. (2018). Fundamentos del concepto de desinformación como práctica manipuladora en la comunicación política y las relaciones internacionales. Historia y Comunicación Social. https://doi.org/10.5209/HICS.59843

Statista. (2020). Ranking de las principales redes sociales a nivel mundial según el número de usuarios mensuales activos en enero de 2020 . https://es.statista.com/estadisticas/600712/ranking-mundial-de-redes-sociales-por-numero-de-usuarios/

Tufte, T. (2017). Communication and social change: A citizen perspective. https://ebookcentral.proquest.com

Villalobos, J. (2020, 26 de junio). 6 pasos para leer notas de COVID-19 con ojo crítico (opinión experta). Tecnológico de Monterrey, Guadalajara. https://tec.mx/es/noticias/guadalajara/salud/6-pasos-para-leer-notas-de-covid-19-con-ojo-critico-opinionexperta

Wordpress. (2008, 28 de junio). Alfabetización digital. APA Style Blog. https://literaciapr. wordpress.com/2008/06/28/definicion-de-alfabetizacion-digital 